Edith Cowan University

Research Online

Research outputs 2014 to 2021

$10-21-2021$

\title{
A preliminary evaluation of a manualised intervention to improve early literacy skills in children with developmental language disorder
}

\author{
Anna Louise Taylor \\ Samuel D. Calder \\ Simmone Pogorzelski \\ Edith Cowan University \\ Lauren Koch
}

Follow this and additional works at: https://ro.ecu.edu.au/ecuworkspost2013

Part of the Language and Literacy Education Commons

$10.1177 / 02656590211052001$

This is an author's accepted manuscript of: Taylor, A. L., Calder, S. D., Pogorzelski, S., \& Koch, L. (2021). A preliminary evaluation of a manualised intervention to improve early literacy skills in children with developmental language disorder. Child Language Teaching and Therapy, 37(3), 321-336. Copyright @ 2021 (SAGE).

https://doi.org/10.1177/02656590211052001

This Journal Article is posted at Research Online.

https://ro.ecu.edu.au/ecuworkspost2013/11615 
A preliminary evaluation of a manualised intervention to improve early literacy skills in children with Developmental Language Disorder

Anna Taylor, Samuel D Calder, Simmone Pogorzelski, Lauren Koch

\section{To cite this article:}

Taylor, A.L., Calder, S.D., Pogorzelski, S. \& Koch, L. (2021) A preliminary evaluation of a manualised intervention to improve early literacy skills in children with Developmental Language Disorder. Child Language, Teaching and Therapy, 37(3) 321-336.

DOI: $10.1177 / 02656590211052001$

\section{Corresponding author:}

Anna Taylor

School of Allied Health

Curtin University

GPO Box U1987, Perth

Western Australia, 6845

Email: anna.benn@ postgrad.curtin.edu.au

\section{Email addresses for all authors:}

Samuel Calder: $\underline{\text { S.Calder@ curtin.edu.au }}$

Simmone Pogorzelski: s.pogorzelski@ecu.edu.au

Lauren Koch: Lauren.Koch@education.wa.edu.au

\section{Conflict of Interest Statement}

The author(s) declared the following potential conflicts of interest with respect to the research, authorship, and/or publication of this article: Anna Taylor, Samuel Calder and Lauren Koch and are affiliated with the Department of Education in Western Australia. Anna Taylor, Simmone Pogorzelski and Lauren Koch are affiliated with MultiLit.

\section{Funding}

The author(s) received no financial support for the research, authorship and/or publication of this article. 


\begin{abstract}
Children with Developmental Language Disorder (DLD) commonly present with oral language weaknesses which disrupt the development of literacy and impede related academic progress. While there is evidence to support the delivery of manualised Tier 2 interventions with this population, little is known about the effects of Tier 1 interventions. A retrospective cohort comparison was used to evaluate whether there was an observable effect of a manualised Tier 1 intervention compared to 'business-as-usual' on early literacy skills for children with DLD. Participants were 140 children attending a specialised education program with equivalent oral language skills and alphabetic knowledge at baseline. After 18 months of formal literacy intervention, both groups were assessed on measures of early literacy skills. The differences between group means on all measures favoured the manualised intervention group, and they performed significantly better on a measure of nonword reading fluency. The findings indicate that a manualised Tier 1 intervention may be advantageous for children with DLD in developing proficiency in phonological recoding. This research contributes to the sparse evidence-base supporting the implementation of Tier 1 interventions for at risk populations, and findings warrant future research using experimental designs with tighter controls.
\end{abstract}

\title{
Keywords
}

Developmental Language Disorder, Response to Intervention, Tier 1 intervention, early literacy, manualised intervention 


\section{Introduction}

The acquisition of literacy is a critical educational achievement for all children. Proficient language skills form the basis of reading development and related academic success (Snow, 2016). Language difficulties are common in young children. Developmental Language Disorder (DLD) affects approximately two in every 30 children in a classroom (Norbury et al., 2016), increasing their risk of literacy difficulties, low educational attainment, and prolonged unemployment (Clegg et al., 2005). Children with DLD are considered vulnerable to reading difficulties because of weaknesses in one or both components of skilled reading, which are described by the Simple View of Reading model as word recognition and language comprehension skills (Gough and Tunmer,1986). The Cognitive Foundations of Learning to Read framework (Tunmer and Hoover, 2019) offers a more detailed breakdown of the subskills which contribute to the development of these essential components. Word recognition develops through the teaching and learning of a set of early literacy skills, which include concepts of print, letter and alphabetic knowledge, and phonemic awareness. Oral language skills in phonology, semantics and syntax accumulate from birth to forma linguistic knowledge base. Once children can decode print and read simple sentences, together with background knowledge, these skills provide an essential foundation for text comprehension (Tunmer and Hoover, 2019).

\section{Learning to read with DLD}

Several studies indicate that around 50\% of children with DLD will develop a reading disability (Catts et al., 2002; McArthur et al., 2000; Tomblin et al., 2000); however, rates as high as $84 \%$ in some cohorts are reported (Botting and Simkin, 2006; Werfel and Krimm, 2017). Differences in the diagnostic criteria used to define cases of DLD may contribute to this variability (Tambyraja and Schmitt, 2020). DLD is considered a heterogeneous condition (Bishop et al., 2017), and individual strengths and weaknesses influence reading performance. Some children with DLD may learn to read accurately and fluently, but deficits in the non-phonological domains of language (i.e., vocabulary, syntax) constrain text level reading comprehension (Nation et al., 2004). Other children with DLD, 
especially those with significant phonological deficits, may struggle to learn the skills necessary to 'crack the alphabetic code'. The development of reading in these individuals may be slow and effortful, and some may meet criteria for a co-occurring diagnosis of dyslexia (Snowling et al.,2019). Werfel and Krimm (2017) classified 32 second to fourth graders with DLD into four reading subtypes based on their performance on word and passage level reading tasks. Typical reading was observed in $16 \%$ of children, all of whom achieved scores in the low average range. Of the $84 \%$ of children classified with reading difficulties, 50\% were considered to have 'garden variety' impairment (poor word and passage level reading), and 25\% met criteria for dyslexia (poor word level reading only). A specific comprehension impairment (poor passage level reading only) was observed in only $9 \%$ of children, indicating that, more often than not, word level deficits are implicated in the reading problems of children with DLD.

\section{Early literacy skills}

Given their vulnerability to reading difficulties, children with DLD should be provided with the best opportunity to experience success in learning to read from the outset of instruction. It is widely accepted that learning to read in English requires formal instruction in early literacy skills (National Reading Panel, 2000). Early literacy skills are primarily alphabetic decoding skills that facilitate the recognition of printed words. Alphabetic decoding is the process of converting letters (or combinations of letters) to sounds and blending those sounds together to read a word (Tunmer and Hoover, 2019). Fundamental to this process is the acquisition of alphabetic code knowledge, or phonics, which is knowledge of how the sounds in English are represented by written symbols (Moats, 2010). When alphabetic code knowledge is complete and can be applied through a whole word, children can independently identify novel written words and, if stored within the lexicon, activate meaning (Ehri, 2014). This method of reading unfamiliar words is known as phonological recoding and is important for both beginning and proficient readers (Share, 1999). Performance on nonword reading tasks provides a valid indication of proficiency in phonological recoding (Castles et 
al., 2018b). The use of nonwords eliminates the possibility of relying upon existing visual knowledge when reading, therefore creating the conditions in which alphabetic knowledge and decoding skills must be applied (Castles et al., 2018a).The ability to phonologically recode unfamiliar words serves as a mechanism for self-teaching in independent reading (Share, 1999), and facilitates the permanent storing of specific letter patterns, or words, in long term memory (Ehri and Snowling, 2004). This process, known as orthographic mapping, supports recognition of words instantly and mapping of sounds-to-letter patterns for spelling. Phonological recoding and orthographic mapping are therefore major contributors to word identification in early reading (Ehri, 2014). There is growing evidence that complementing phonics instruction with decodable texts and accompanying instructional strategies in the early stages of reading may be advantageous in the development of alphabetic decoding skills (Mesmer, 2000).

\section{Response to intervention}

Individuals with DLD do not require teaching of different sets of skills than their typically developing peers, however some may require more intense or specialised intervention (Ebbels et al.,2019). The three-tiered Response to Intervention (RtI) model (Fuchs and Fuchs, 2006) offers a framework for schools to support the delivery of high-quality reading intervention to all, including those with disabilities. RtI begins with the delivery of evidence-based teaching for all (Tier 1), followed by small group interventions targeting specific skills (Tier 2), and individualised, intensive interventions delivered by speech-language pathologists or highly trained educators (Tier 3). Evidence-based reading intervention at Tier 1 mitigates the number of children who need more intensive support at the other Tiers, and reserves resources and expertise for those needing them most (Snow, 2016).

\section{Manualised interventions}


Integral to RtI is the delivery of Tier 1 curriculums which effectively support $80 \%-90 \%$ of children to be successful learners without the need for further intervention. However, translating the vital components of reading instruction to practice is hindered by a shortfall in teacher knowledge of language constructs (Stark et al., 2016). In an effort to support teachers to successfully teach all children to learn to read, it is common for Australian schools to adopt manualised interventions (Campbell, 2020). Manualised interventions are typically published programs which prescribe learning goals, steps for teaching, instructional strategies, correction procedures, and success criteria. Evidence-based manualised interventions of early literacy use teaching strategies grounded in rigorous research and prescribe the systematic and explicit teaching of synthetic phonics (Rowe, 2006). Often scripted, manualised interventions promote consistency in teaching across a range of educators, regardless of their level of experience (Plavnick et al., 2015). Whole-school adoption of manualised programs facilitates low variability teaching, which has been identified as a common characteristic of high performing schools (Louden, 2015). The use of manualised Tier 2 oral language interventions is well supported (Ebbels et al., 2019). In a randomised control trial, Fricke et al., (2013) evaluated the effects of a manualised early oral language intervention delivered to 180 nursery students in the United Kingdom (UK). The children who received the intervention showed significantly stronger oral language and narrative skills than those who were allocated to a wait-list control group. In the United States, Justice et al., (2010) found that 11 classrooms of children whose teachers delivered a manualised storybook-based intervention demonstrated stronger skills in grammar, vocabulary, and phonological awareness than those attending nine comparison classrooms.

\section{Tier 1 Interventions}

Although the first formal experiences in learning to read for most children with DLD occur in a classroom, there is very little research regarding how well their learning needs are met in this context. A recent study by Wilcox et al., (2020) established efficacy for a manualised Tier 1 curriculum: Teaching Early Literacy and Language (TELL). Classes of preschool children with 
speech and language impairments were randomly assigned to receive either TELL or the 'business as usual'(BAU) curriculum. Teachers who delivered TELL were provided with a detailed scope and sequence, training, materials, and lesson plans. Teachers in the BAU group delivered a curriculum in line with 'state approved learning standards', which included the same oral language and emergent literacy target elements of TELL (e.g., phonological awareness, print knowledge, vocabulary, listening comprehension). Observations of both groups found that children who received BAU were less likely to receive explicit instruction in all the target elements. Further, delivery of TELL resulted in higher intensity instruction through the provision of differentiated small group work (Wilcox et al., 2020). This study offers promise that a manualised Tier 1 program may be advantageous for children with DLD, yet further research beyond the emergent phase of literacy development is needed. While studies investigating the effects of manualised Tier 1 programs for children with DLD that specifically target the development of early literacy skills are limited, high quality universal programs may offer promise. InitiaLit (MultiLit, 2017), is a highly structured Tier 1 intervention that provides explicit, scripted instruction in the essential components of literacy for the first three years of formal years of schooling. In the first two years, there is a strong focus on the development of the skills that enable accurate word recognition. In the third year, the focus expands to include reading fluency and comprehension. Prior to its publication, research trials of InitiaLit involving 155 Year 1 students in mainstream schools reported that 20 weeks of intervention resulted in significant gains on measures of early reading skills, with large effect sizes (MultiLit,2020). Research by Bell et al., (2020) found that a large proportion (82\%) of children who received InitiaLit were able to achieve the expected level of proficiency in early word recognition skills, as indicated on their performance on the UK's Year 1 Phonics Screening Check (Standards and Testing Agency, 2011).

\section{Objectives}

Undoubtedly, many children with DLD will require support in developing the complex skills that underpin early literacy, however the instructional factors that influence their progress are not well 
understood (Adlof, 2017). Little is known about the effects of high-quality Tier 1 interventions on the early literacy skills of this population, or whether a manualised intervention is advantageous over a customised approach. The current study therefore aimed to report on the observed effects of a manualised Tier 1 intervention on the development of early literacy skills of children with DLD. We hypothesised that for children with DLD, the manualised Tier 1 intervention would improve word and nonword reading fluency, passage reading fluency and nonword spelling accuracy significantly more than BAU.

\section{Methods}

\section{Study design}

The current study implemented a retrospective cohort control comparison research design and was not a planned comparison of intervention between two groups. Therefore, reporting follows the Strengthening the Reporting of Observational Studies in Epidemiology (STROBE) Statement (Von Elm et al., 2008). Children in the manualised group received intervention from the onset of formal schooling in $2018(5 ; 5-6 ; 5$ years) to mid-Year 1 in $2019(6 ; 5-7 ; 5$ years $)$ and were tested midway through 2019 on measures of early literacy skills. The BAU group received standard practice for the same duration in 2017 to 2018 and were tested midway through Year 1 on the same measures, therefore functioning as a retrospective cohort comparison group. Ethical approval for the study was obtained from the Western Australian Department of Education.

\section{Setting}

All data were collected in Perth, Western Australia from children attending a specialised educational program designed to cater for early school-aged children with DLD. In this setting teachers and speech-language pathologists work collaboratively to design and deliver specialised speech, language and literacy interventions. The school employs a contextualised approach to oral language intervention (Gillam et al., 2012), delivering meaningful instruction based around topics within the 
mandated curriculum (School Curriculum and Standards Authority, 2016). Alongside this, all children receive instruction in synthetic phonics beginning in the pre-primary year, as directed by the Department of Education of Western Australia (2016). Children with additional learning needs are supported through interventions that focus on developing specific skills such as phonology.

\section{Participants}

The participants in this study were referred to the specialised educational program, and acceptance into this program was dependent on them meeting current diagnostic criteria for DLD (Bishop et al.,2017). Children attending have demonstrated significant and persistent oral language problems that impede functioning in life areas related to language. Assessment to determine eligibility occurs in the year prior to placement, and combines data from multiple sources, including reports from parents and teachers, standardised and criterion referenced tests, and the assessment of discourse. School-designed parent and teacher questionnaires and interviews investigated the functional impact of language difficulties on activities of everyday life, and the presence of risk factors of persisting problems. Children accessing the program reside within the school's intake area, which spans over 78 metropolitan suburbs of Perth. While data pertaining to the socio-economic status of each individual was not available to the authors in this study, longitudinal data suggests a trend for 50\% $60 \%$ of school families to place in the middle quartiles of the Index of Community Socio-educational Advantage, $25 \%-30 \%$ in the bottom quartile, and $15 \%-20 \%$ in the top quartile (Australian Curriculum, Assessment and Reporting Authority, 2020). As the school intake area remained constant for the duration of the study, it is reasonable to assume that the two groups were of similar socio-economic composition. Within the BAU group, $43.9 \%$ of participants commenced their educational placement in Kindergarten and $56.1 \%$ in Pre-primary. Similar proportions were observed in the manualised intervention group, with $36.5 \%$ commencing in Kindergarten and $63.5 \%$ in Preprimary. A Pearson's chi-square test of contingencies indicated there were no significant differences between groups in relation to when children commenced placement, $\chi 2(1, \mathrm{~N}=140)=.807, \mathrm{p}=.369$. 
The children who did not attend the school in Kindergarten received this year of schooling in a mainstream setting. In Western Australia, kindergarten has a specific emphasis on providing playbased learning for the development of communication, social and emotional development (Australian Government Department of Education, Skills and Employment,2016). While some informal teaching of emergent literacy skills (e.g., rhyme, alphabet knowledge) may occur in the kindergarten year, formal daily literacy instruction does not typically commence until the pre-primary year.

\section{Variables}

\section{Independent variables}

Manualised intervention. Children in the manualised group received InitiaLit (MultiLit, 2017). Staff received materials, lesson scripts and formal training. Lessons were delivered four times per week for 90 min per day. Only decodable texts were used in the reading component of the program. As prescribed by the program, monitoring occurred at regular intervals and informed referrals for Tier 2 and 3 interventions. To assist with faithful delivery of the program, lessons were regularly observed, and feedback was provided to teachers based around a set of criteria. However, treatment fidelity was not formally evaluated. Business-as-usual (BAU) intervention. Prior to the introduction of the InitiaLit, a custom designed, curriculum-based Tier 1 intervention was implemented. Designed by school-based speech-language pathologists, the intervention was based on a phonological processing model (Stackhouse and Wells, 1997), and a framework for phonological awareness intervention (Schuele and Boudreau, 2008). Training and support from speech-language pathologists was avail-able to teachers, who were responsible for planning and delivering the intervention program. Lessons focused on the development of alphabetic knowledge and phonological awareness, with an emphasis on the development of phoneme blending and segmenting. The phonics component was taught using systematic, synthetic instructional strategies adapted from a commercial phonics program (Lloyd, 1993). Alongside this, high-frequency words were taught using rote memorisation strategies. Lessons took place five times per week for 75 min 
per day. Beyond suggested phrasing for specific phonemic awareness skills, scripting was not used. A mix of decodable and predictable texts and related word recognition strategies were utilised, at the discretion of the teacher. Progress monitoring was the responsibility of individual teachers and informed planning. Cohort level assessment and data analysis occurred biannually. Additional Tier 2 and 3 intervention was provided based on referrals from concerned teachers. As demonstrated by a comparison of the interventions in Appendix A, the manualised and BAU interventions were similar in that they both taught early literacy skills for word recognition using an explicit, direct and systematic instructional approach. The key differences between the programs include: the level of program structure (InitiaLit-high, BAU-low), use of scripting (InitiaLit-scripted, BAU-unscripted), schedule of assessment (InitiaLit-regular, BAU-biannual, or at teacher discretion), and the types of text used in the group reading component (InitiaLit-decodable only, BAU-decodable, predictable and levelled texts). Neither the BAU or the manualised intervention group practised reading nonwords.

Dependent variables. The primary dependent variables were early literacy skills, specifically, word and nonword reading fluency, nonword spelling accuracy, and passage reading fluency. Measures for each of these skills are reported below. Baseline variables and behavioural controls. To establish whether groups were homogenous enough to make between group comparisons, we evaluated whether language and alphabetic knowledge were similar at entry to the specialised program. Further, we used a behavioural control measure of math performance to determine whether children in both groups were similar at the same age when tested on early literacy skills.

\section{Data sources}

\section{Early literacy skills}

While regular data collection for planning and progress monitoring is part of standard practice in the educational setting, additional measures were collected to assist with the implementation of the manualised intervention. 
The Wheldall Assessment of Reading Lists (WARL) (Wheldall et al., 2015). The WARL is a curriculum-based measure of word reading fluency. Children read from three lists of 100 regular and irregular words for one minute per list. The results are averaged to calculate the number of words reads correctly per minute. Benchmarks for years 1 and 2 indicate expected levels of performance at key points of the school year. These were established from two Australian schools per-forming at state average levels on the National Assessment Program-Literacy and Numeracy (NAPLAN). Children are identified as needing targeted support if they achieve a score below the $25^{\text {th }}$ percentile. The WARL has been found to have high parallel forms reliability (0.93-0.96) and correlates highly and significantly with other established measures of reading skills (0.66-0.95) (Wheldall et al., 2015).

Wheldall Assessment of Nonword Reading (WARN) (Wheldall et al., 2021). Children read from three lists of 100 regular words for 30 seconds per list. The results are averaged to calculate the number of words reads correctly per 30 seconds. Benchmarks for pre-primary and year 1 at the middle and end of the school year indicate expected levels of performance. These were established from four Australian schools performing at state average levels on NAPLAN. Children are identified as needing targeted support if they achieve a score below the $25^{\text {th }}$ percentile. The WARN has high parallel forms reliability (0.97-0.98) and correlates highly and significantly with other established measures of reading skills (0.85-0.92) (Wheldall et al., 2021).

Sutherland Phonological Awareness Test-Revised (SPAT-R) (Neilson, 2003). Nonword spelling was measured using the SPAT-R, a standardised assessment of phonological awareness skills and the reading and spelling of nonwords. Children were asked to spell eight orally presented nonsense words. The test is reported to have high internal consistency (0.82-0.84) (Neilson, 2003).

CUBED Narrative Language Measures-Reading (Petersen and Spencer, 2016). Passage reading fluency was measured using the CUBED Narrative Language Measures-Reading (NLM-R). 
Children read aloud a short text of 130 words while timed for one minute. A decoding fluency score is determined by summing the words read correctly within the minute.

\section{Baseline language and alphabetic knowledge}

Baseline language data were accessed through the children's enrolment package, which included results of the Clinical Evaluation of Language Fundamentals Preschool (second edition) (CELF-P2). The CELF-P2 assess language skills that are fundamental to developing effective communication. The test was normed for use in Australia and has high internal consistency(r=0.92) (Wiig et al., 2004).

As part of routine data collection, a school-designed alphabetic knowledge assessment of lower-case letter names and corresponding sounds was individually administered to all participants on entry to pre-primary. Alphabetic knowledge is considered a critical component of reading and spelling development (Ehri and Snowling, 2004). A raw score for letter-name and letter-sound out of 26is obtained by tallying the number of correct responses.

Control measure. Math skills were tested at the end of Year 1 for all children. Scores from Progressive Achievement Test in Mathematics (PAT-M) were used as a behavioral control. The Year 1 test contains 30 questions and was normed on 51,694 children. The norm reference sample mean scale score was 93.2 with a standard deviation of 14.6 (ACER, 2016)

Bias

The current study was non-confirmatory, therefore there should have been no influence of bias on standard practice. There was no a priori power estimates, but rather the sample size was determined as per intake to the specialised educational program. Nonetheless, post hoc power estimates suggested the study is sufficiently powered to detect medium to large effects using the statistical methods described below.

\section{Quantitative variables}


The research question of interest relates to whether or not there were observable differences between groups who received BAU or a manualised Tier 1 intervention. Continuous demo-graphic variables (such as age) were not categorised for analysis and presentation. Early literacy skills were the primary dependent variables of interest, and measured at word level through the WARL, WARN and SPAT-R, and; at text level through the NLM-R. Since the demands of text level reading increases markedly from word level, these tools measure different skills. Therefore, these variables have been separated as such for analysis (i.e., word and text level). Baseline and control variables were also considered separately as they were not expected to change between groups.

\section{Results}

\section{Participants}

Data for a total of 140 children with DLD were extracted, with $n=66$ in the BAU group, and $n=74$ in the manualised intervention group. Only data for children who received assessments in Year 1 were considered for analyses, therefore there was no loss to follow up.

\section{Descriptive data}

For the BAU group, ages ranged from $6 ; 1-7 ; 0$ years with a mean of $6 ; 5$ years ( $\mathrm{SD}=0 ; 3$ years) at the end of Year 1 testing point in 2018. There were 51 males (77.3\%) and 15 females (22.7\%). For the manualised intervention group, ages ranged from $6 ; 1-7 ; 1$ years with a mean of $6 ; 6$ years $(\mathrm{SD}=0 ; 4$ years) at the end of Year 1 testing point in 2019. Of the participants, 56 were male (75.7\%) and 18 were female $(24.3 \%)$.

Baseline. An independent samples t-test revealed no group differences on CELF-P2 entry scores, $\mathrm{t}$ $(133)=1.12, \mathrm{p}=.25$, two-tailed, or measures of letter sound knowledge, $\mathrm{t}(138)=.71, \mathrm{p}=.12$, twotailed, and; letter name knowledge, $\mathrm{t}(138)=.79, \mathrm{p}=.52$, two-tailed. We planned to compare means on PAT-M results with an independent samples t-test, however the assumption of normality was violated for the BAU group (Kurtosis $=3.54 ; 330$ Shapiro-Wilk statistic, $\mathrm{p}=.002$ ), so group differences were analysed with a nonparametric Mann-Whitney U test. Results indicated that the 
mean score $(\mathrm{M}=98.78)$ on PAT-M for the manualised intervention group $($ Mean Rank $=78.91, \mathrm{n}=$ 72) was significantly higher than the mean score $(M=94.77)$ of the BAU group (Mean Rank = $59.23, \mathrm{n}=66), \mathrm{U}=1698.50 \mathrm{z}=-2.89, \mathrm{p}=.004$. Therefore, although there were no between group differences on language and baseline alphabetic knowledge, the manualised intervention group also performed better at math as well as on the WARN, when we expected there to be no group differences on math scores as a behavioural control.

\section{Outcome data}

Main results. All outcome data are reported in Table 1. A multivariate analysis of variance (MANOVA) was used to examine whether there were between group differences on measures of early literacy skills. Assumption tests revealed normality and homogeneity of variance-covariance were violated, however since the sample size was larger than 40, the MANOVA was considered robust against violations of normality. Correlations between dependent variables did not exceed $\mathrm{r}=$ .90 indicating multicollinearity was not of concern. Analysis showed there was a significant effect of the group variable (BAU vs. manualised intervention program) on combined word level early literacy dependent variables (WARN, WARL, SPAT-R), F (3135) = 7.24, p<.001, $\eta 2=.139$. Analysis of dependent variables showed no effect on the WARL or SPAT-R. The mean score on the WARN for the manualised intervention $(M=12.41)$ was significantly higher than that of the BAU group $(M=8.14)$ at a Bonferroni adjusted alpha level of $.017, F(1,137)=11.24, p=.001, \eta 2=.076$. An independent samples t-test was planned to compare means on NLM-R results; however, normality was violated for both groups (Shapiro-Wilk statistic: $\mathrm{p}<.001$ ). Therefore, a nonparametric Mann Whitney U test was used. The test indicated that the mean NLM-R score $(\mathrm{M}=27.65)$ for the manualised intervention group (Mean Rank $=73.62, \mathrm{n}=74$ ) was higher than the mean score $(M=19.86)$ for the BAU group (Mean Rank $=67.00, n=66)$, but the test was non-significant, $U=$ $2211, \mathrm{z}=-.97, \mathrm{p}=.334$. 
Table 1. Means and standard deviations of baseline and outcome data.

\begin{tabular}{llll} 
Measures & $\begin{array}{l}\text { Manualised intervention } \\
M(S D ; \text { range })\end{array}$ & $\begin{array}{l}\text { Business-as-usual } \\
M(S D)\end{array}$ & Effect size \\
\hline CELF-P2 Core Language & & & \\
Score on entry & $68.3(10.6 ; 45-90)$ & $70.6(12.1 ; 45-102)$ & .20 \\
Sound Letter at baseline & $10.9(9.3 ; 0-26)$ & $12.1(10.0 ; 0-26)$ & .10 \\
Letter Name at baseline & $6.1(8.8 ; 0-26)$ & $7.3(8.5 ; 0-26)$ & .10 \\
WARL & $33.7(23.6 ; 0.33-95.3)$ & $27.6(20.1 ; 2.0-84.0)$ & .32 \\
WARN & $12.4(8.7 ; 0-35.0)^{*}$ & $8.1(6.3 ; 0-27.3)$ & .61 \\
SPAT-R & $31.0(8.7 ; 6.0-42.0)$ & $30.1(7.8 ; 11.0-41.5)$ & .14 \\
CUBED NLM-R & $27.7(30.0 ; 0-102)$ & $19.9(23.9 ; 0-89.0)$ & .33 \\
PAT-M & $98.8(7.2 ; 85.1-113.2)^{*}$ & $94.8(7.4 ; 62.4-109.1)$ & .58 \\
\hline
\end{tabular}

Notes: $M=$ mean; $S D=$ standard deviation; Cohen's $d$, where $d=.20$ is small, $d=.50$ is medium, and $d=$ .80 is large.

\section{Other analyses}

The percentage of the sample of students within the BAU group and the manualised intervention program group meeting benchmark on the WARN, WARL and NLM-R are presented in Table 2. Referencing performance of students on benchmarks determined on mainstream norms allows for a tentative comparison of literacy skills given grade level expectancy. A Pearson's chi-square test of contingencies (with $\alpha=.05$ ) was used to evaluate whether BAU intervention or manualised program was related to whether or not children perform at or above benchmark on the WARN. The chi-square test was statistically significant, $\chi 2(1, \mathrm{~N}=140)=5.39, \mathrm{p}=.02$. However, the association between intervention groups and performing at or above benchmark was small, $\varphi=.20$. Children who received the manualised intervention program were significantly more likely to perform at or above benchmark than children receiving BAU. Nonetheless, a larger proportion of both groups still performed below benchmark. A chi-square test also revealed a significant relationship of group conditions and achieving benchmark on the WARL, $\chi 2(1, \mathrm{~N}=140)=5.21, \mathrm{p}=.02$, with a small effect, $\varphi=.19$. The chi-square test for the NLM-R was non-significant, $\chi^{2}(1, N=140)=5.16, p=.08$. Since there were no differences between groups on these measures resulting from the MANOVA, we limit discussion on these analyses. 


\section{Discussion}

\section{Key results}

The current study used a retrospective cohort control comparison design to determine whether there were observable differences between groups of children with DLD on early literacy skills following a period of Tier 1 manualised intervention compared to BAU. Analyses revealed that both groups were comparable on baseline language and alphabetic knowledge, but those who received manualised early literacy intervention demonstrated significantly better nonword reading fluency. Since there was no difference between groups on language or alphabetic skills, this may be evidence of a treatment effect. Although mean scores on all other early literacy measures were higher for the manualised intervention group, analyses revealed these differences to be non-significant. Analyses of scores in relation to grade level benchmarks revealed those who received the manualised intervention were significantly more likely to achieve an expected level of performance on measures of word and nonword, but not text level, reading fluency. Analysis of performance on a behavioural control measure of math skills revealed that the manualised intervention group had a higher mean score than the BAU group when we expected no differences as a result of intervention.

Table 2. Percentage of students who achieved benchmark on the WARN, WARL and NLM-R Scripted intervention

\begin{tabular}{lll} 
& Scripted intervention & Business as usual \\
\hline WARL & $29.7 \%^{*}$ & $13.6 \%$ \\
WARN & $44.6 \% *$ & $28.5 \%$ \\
CUBED NLM-R & $25.7 \%$ & $13.6 \%$ \\
\hline${ }^{*} p<.05$ & &
\end{tabular}

\section{Interpretation}

The significantly higher scores on the timed test of nonword reading achieved by the manualised intervention group indicates greater automaticity (i.e., fluency) in applying alphabetic knowledge and decoding skills when reading unfamiliar words. Given the critical role of phonological recoding in the development of orthographic mapping for fluent reading (Ehri and Snowling, 2004; Share,1999), 
the authors of this study contend that the children who received the manualised intervention are better positioned for further progress in reading than the BAU group. Effortless word recognition allows cognitive resources to be directed to understanding what is read (Castles et al., 2018a), and establishing proficient word recognition skills in the early stages of reading may therefore be beneficial for children with DLD. The key differences between the manualised and BAU interventions may explain the significant result observed in this study. Firstly, as both interventions taught early literacy skills explicitly and systematically, we propose that the whole school adoption of a highly structured program intervention reduced within-school variability of lesson design. Adherence to the daily lesson schedule of the manualised intervention (i.e., 20-25 minutes of wholeclass explicit teaching, followed by 30-45 minutes of small group work) maximised opportunities for teaching, practise and consolidation of the target skills. BAU did include whole class and small group work, but the time allocated to each was directed by the teacher. Secondly, we propose that the use of scripting in the manualised intervention resulted in more rigorous delivery of an explicit teaching framework. An explicit approach is proven to be of benefit for children with DLD when they are learning new skills, such as vocabulary (Steele and Mills, 2011), oral narrative (Westerveld and Gillon, 2008), and grammar (Calder et al., 2021). Thirdly, the frequent monitoring schedule of the manualised intervention identified individual learning needs of children. Referrals to Tier 2 or 3 interventions were informed by data, rather than teacher concern. Finally, alignment of the decodable readers with the phonics teaching of the manualised intervention is likely to have resulted in increased opportunities for practice in applying alphabetic decoding skills. The non-significant difference between group performance on the WARL may be accounted for by the intensive focus on high-frequency word instruction in the BAU group. Alternatively, the manualised intervention prioritised the development of alphabetic knowledge and decoding skills, as high-frequency irregular word reading develops later, and more easily, after practise using known common letter-sound correspondences to read phonetically regular words (Share,1999).We had anticipated that group 
comparisons would be feasible, and evidence of a treatment effect would be interpretable if both groups were equivalent on baseline measures of language functioning (i.e., the CELF-P2) and alphabetic knowledge, as well as an unrelated behavioural academic control measure postintervention measure (i.e., PAT-M). While there were no differences between groups on the CELFP2 and alphabetic knowledge assessments, analyses revealed that there was a significant difference between groups on PAT-M, favouring the manualised intervention group. When interpreting the comparison on this measure, the use of PAT-M as a standard score should be considered. A score of 93.2 on PAT-M reflects the average based on age equivalency and both groups achieved a mean score within the average range using a one standard deviation cut off (i.e., 93.2-14.6=78.6 cut score). This indicated that there may be no meaningful difference between groups in terms of their math skills in practice or in an educational attainment sense. In contrast, children who received the manualised intervention were significantly more likely to reach or exceed the expected standard of academic skills related to word level reading than those who received BAU. However, the proportion of students able to perform at or above the benchmark continued to fall well below that typically observed in mainstream classrooms (i.e., $80 \%-90 \%$ ).

\section{Generalisability}

It is difficult to discuss generalisation to current practices and policies given the preliminary nature of these findings. Specifically, causal links between intervention conditions and effects must be interpreted with caution considering the study design. Nonetheless, as there is a paucity in evidence supporting Tier 1 interventions for children with DLD (Ebbels et al., 2019), practitioners may use findings from the current study as a basis for planning the implementation of Tier 1 interventions in classrooms. Although we did not have the ideal controls in place to interpret a causal effect, the current study represents the potential for a manualised intervention to improve early literacy outcomes for children with DLD in school contexts. It is, however, unclear if the approach improves reading comprehension or related academic outcomes, or if it mitigates the need for further support 
at Tiers 2 and 3. Future studies may aim to consider the long-term benefits of manualised interventions for children with DLD. While conducting research in everyday settings is challenging, it is hoped this study may encourage others to critically appraise their practices, especially when evidence in the literature is sparse. This may help to bridge the gap between research and practice, and ultimately improve outcomes for this at-risk and under-researched population.

\section{Limitations}

There are limitations to this study. Firstly, as stated above, the study design is not suited to confirmatory hypotheses as it is observational in nature. Therefore, we were not positioned to test the null hypothesis regarding the benefit of a manualised intervention and controlling for confounding variables. Currently, the treatment effect is interpreted as a difference between similar groups of atrisk children at a single time point on the same measures of early literacy skills. It is difficult to infer a causal relationship without a pre-post control group. Further, while it was evident the children had the same oral language and alphabetic knowledge for the development of reading, we did not collect data pertaining to word level reading abilities prior to intervention commencing, nor did we conduct a formal evaluation of fidelity. Lastly, there is the risk of spectrum or ascertainment bias from using children from specialised educational program (i.e., referral bias), so any evidence of a treatment effect may not generalise to all children with DLD. It is also important to note that the focus of this study was limited to investigating the effects of manualised intervention on the skills that contribute to the word recognition component of skilled reading. The importance of the ongoing delivery of interventions in syntax, semantics and oral narrative to support academic and social functioning for this population cannot be overstated.

\section{Conclusion}

The current study provides preliminary evidence of an advantage to providing manualised Tier 1intervention to children with DLD. Interpretation and generalisability of these findings are limited by the study design, which is observational in nature. The advantage of manualised intervention on 
the various measures of early literacy may indeed be more observable in tightly con-trolled trials testing a priori established hypotheses. Despite its limitations, this study contributes to the evidence base for how early literacy skills in children with DLD can be addressed at Tier 1. Further research to compare effects of manualised programs with experimental research designs to inform best practice for early school-aged children at risk of literacy difficulties is warranted.

\section{Acknowledgements}

The authors would like to acknowledge the contribution made by the speech-language pathologists, teachers, administrators and student educators at the specialised education program who assisted with assessments.

\section{ORCID iDs}

Anna Louise Taylor https://orcid.org/0000-0001-7631-4602

Samuel David Calder https://orcid.org/0000-0001-6064-5837

\section{References}

Adlof SM (2017) Understanding word reading difficulties in children with SLI. Perspectives ASHA Special Interest Groups 2: 71-77.

Australian Council for Educational Research (2016) PAT Maths Norm Update. Australian Council for Educational Research. Camberwell: VIC.

Australian Curriculum, Assessment and Reporting Authority (2020) My School. Available at: https://www.myschool.edu.au/ (accessed 18 October 2020).

Australian Government Department of Education Skills and Employment (2016) Belonging, Being and Becoming-The Early Years Learning Framework. Available at: https://www.education.gov.au/early-years-learning-framework-0 (accessed 26 October 2020).

Bell N, Farrell-Whelan M, and Wheldall K (2020) Use of early word-reading fluency measures to predict out-comes on the phonics screening check. Australian Journal of Education 64(2): $161-176$.

Bishop DV, Snowling MJ, Thompson PA, et al. and the CATALISE-2 consortium (2017) Phase 2 of CATALISE: A multinational and multidisciplinary delphi consensus study of problems with 
language development: Terminology. Journal of Child Psychology and Psychiatry 58(10): 1068-1080.

Botting N and Simkin Z (2006) Associated reading skills in children with a history of specific language impairment (SLI). Reading and Writing 19: 77-98.

Calder SD, Claessen M, Ebbels S, et al. (2021) The efficacy of an explicit intervention approach to improve past tense marking for early school-age children with developmental language disorder. Journal of Speech, Language, and Hearing Research 64(1): 91-104.

Campbell S (2020) Teaching phonics without teaching phonics: Early childhood teachers' reported beliefs and practices. Journal of Early Childhood Literacy 20(4): 783-814.

Castles A, Rastle K, and Nation K (2018a) Ending the reading wars: Reading acquisition from novice to expert. Psychological Science in the Public Interest 19(1): 5-51.

Castles A, Polito V, Pritchard S, et al. (2018b) Do nonword reading tests for children measure what we want them to? An analysis of year 2 error responses. Australian Journal of Reading Difficulties 23(2): 153-165.

Catts HW, Fey ME, Tomblin JB, et al. (2002) A longitudinal investigation of reading outcomes in children with language impairments. Journal of Speech Language and Hearing Research 45(6): 1142-1157.

Clegg J, Hollis C, Mawhood L, et al. (2005) Developmental language disorders - a follow-up in later adult life. Cognitive, language and psychosocial outcomes. Journal of Child Psychology Psychiatry 46 (2):128-149.

Department of Education Western Australia (2016) Focus 2016: Directions for schools. Available at http://det.wa.edu.au/policies/detcms/policy-planning-and-accountability/policiesframework/strategic-documents/focus-2016.en?cat-id=3457058 (accessed 26 October 2020).

Ebbels SH, McCartney E, Slonims V, et al. (2019) Evidence-based pathways to intervention for children with language disorders. International Journal of Language and Communication Disorders 54(1): 3-19.

Ehri LC (2014) Orthographic mapping in the acquisition of sight word reading, spelling memory and vocabulary learning. Scientific Studies of Reading 18(1): 5-21.

Ehri LC and Snowling MJ (2004) Developmental variation in word recognition. In: Stone AC, Silliman ER, Ehren BJ, and Apels K (eds) Handbook of Language and Literacy: Development and Disorders. New York: Guildford Press, 443-460.

Fricke S, Bowyer-Crane C, Haley AJ, et al. (2013) Efficacy of language intervention in the early years. Journal of Child Psychology and Psychiatry 54(3): 280-290.

Fuchs D and Fuchs LS (2006) Introduction to response to intervention: What, why, and how valid is it? Reading Research Quarterly 41(1): 93-99. 
Gillam SL, Gillam RB, and Reece K (2012) Language outcomes of contextualized and decontextualized language intervention: Results of an early efficacy study. Language, Speech, and Hearing Services in Schools 43(3): 276-291.

Gough P and Tunmer W (1986) Decoding, reading, and reading disability. Remedial and Special Education 7:6-10.

Justice LM, McGinty AS, Cabell SQ, et al. (2010) Language and literacy curriculum supplement for pre-schoolers who are academically at risk: A feasibility study. Language, Speech and Hearing Services in Schools 41(2): 161-178.

Lloyd S (1993) The Phonics Handbook. Essex, UK: Jolly Learning.

Louden W (2015) High performing primary schools: What do they have in common? Available at: https://www.ldaustralia.org/client/documents/High_performing_primary_schools__what_they_have_in_common_Louden_2015\%20(002).pdf (accessed 12 February 2020).

McArthur GM, Hogben JH, Edwards VT, et al. (2000) On the "specifics" of specific reading disability and specific language impairment. Journal of Child Psychology and Psychiatry 41(7): 869-874.

Mesmer HA (2000) Decodable text: A review of what we know. Reading Research and Instruction 40(2):121-141.

Moats LC (2010) Speech to Print: Language Essentials for Teachers. Baltimore: Paul H Brooks.

MultiLit (2017) InitiaLit-F Manual. Sydney: MultiLit Pty Ltd

MultiLit (2020) InitiaLit Research Summary. Available at https://multilit.com/wpcontent/uploads/InitiaLit-Research-Summary.pdf (accessed 12 February 2020).

Nation K, Clarke P, Marshall CM, et al. (2004) Hidden language impairments in children. Journal of Speech, Language and Hearing Research 47(1): 199-211.

National Reading Panel (2000) Teaching Children to Read: An Evidence-Based Assessment of the Scientific Research Literature on Reading and its Implications for Reading Instruction. Washington, DC: U.S. Department of Health and Human Services National Institutes of Child Health and Human Development.

Neilson R (2003) Sutherland Phonological Awareness Test Manual. Jamberoo: Language Speech and Literacy Services.

Norbury CF, Gooch D, Wray C, et al. (2016) The impact of nonverbal ability on prevalence and clinical presentation of language disorder: Evidence from a population study. Journal of Child Psychology and Psychiatry 57(11): 1247-1257.

Petersen DB and Spencer T (2016) Cubed Examiners Manual. Language Dynamics Group. https://www.languagedynamicsgroup.com/cubed/cubed_download/ (accessed 12th February, 2020) 
Plavnick JB, Marchand-Martella NE, Martella R, et al. (2015) A review of explicit and systematic scripted instructional programs for students with autism spectrum disorder. Review Journal of Autism and Developmental Disorders 2(1): 55-66.

Rowe K (2006) Effective teaching practices for students with and without learning difficulties: Issues and implications surrounding key findings and recommendations from the national inquiry into the teaching of literacy. Australian Journal of Learning Disabilities 11(3): 99115.

School Curriculum and Standards Authority (2016) Western Australian curriculum \& assessment outline. Available at: https://k10outline.scsa.wa.edu.au/home/teaching/curriculum-browser (accessed 18thOctober 2020).

Schuele M and Boudreau D (2008) Phonological awareness intervention: Beyond the basics. Language, Speech and Hearing Services in Schools 39(1): 3-20.

Share D (1999) Phonological recoding and orthographic learning: A direct test of the self-teaching hypothesis. Journal of Experimental Child Psychology 72(2): 95-129.

Snow PC (2016) Elizabeth usher memorial lecture: Language is literacy is language - positioning speech-language pathology in education policy, practice, paradigms and polemics. International Journal of Speech-Language Pathology 18(3): 216-228.

Snowling MJ, Nash HM, Gooch DC, et al. (2019) Developmental outcomes for children at high risk of dyslexia and children with developmental language disorder. Child Development 90(5): $458-564$.

Stackhouse J and Wells B (1997) Children's Speech and Literacy Difficulties: A Psycholinguistic Framework. London: Whurr.

Sutherland D and Gill. Standards and Testing Agency (2011) Year 1 Phonics Screening Check: Pilot 2011: Technical Report. Department for Education. Available at:

https://www.gov.uk/government/publications/phonics-screening-check-pilot-2011-technicalreport (accessed 12th February, 2020).

Stark HL, Snow PC, Eadie PA, et al. (2016) Language and reading instruction in early years' classrooms: The knowledge and self-rated ability of Australian teachers. Annals of Dyslexia 66(1): $28-54$.

Steele SC and Mills MT (2011) Vocabulary intervention for school-age children with language impairment: A review of evidence and good practice. Child Language Teaching and Therapy 27(3): 354-370.

Tambyraja SR and Schmitt MB (2020) Embedding evidence-based practices to address literacy in school-based speech-language therapy. Topics in Language Disorders 40(4): 341-356.

Tomblin JB, Zhang X, Buckwalter P, et al. (2000) The association of reading disability, behavioral disorders, and language impairment among second-grade children. Journal of Child Psychology and Psychiatry 41(4): 473-482. 
Tunmer WE and Hoover WA (2019) The cognitive foundations of learning to read: A framework for preventing and remediating reading difficulties. Australian Journal of Learning Difficulties 42(1): 75-93.

Von Elm E, Altman DG, Egger M, et al. (2008) The strengthening the reporting of observational studies in epidemiology (STROBE) statement: Guidelines for reporting observational studies. Journal of Clinical Epidemiology 61(4): 344-349.

Werfel KL and Krimm H (2017) A preliminary comparison of reading subtypes in a clinical sample of children with specific language impairment. Journal of Speech, Language and Hearing Research 60(9): 2680-2686.

Westerveld M and Gillon G (2008) Oral narrative intervention for children with mixed reading disability. Child Language Teaching and Therapy 24(1): 31-54.

Wheldall K, Reynolds M, and Madelaine A (2015) The Wheldall Assessment of Reading Lists (WARL) Manual. Sydney: MultiLit Pty Ltd

Wheldall K, Reynolds M, Madelaine A, et al. (2021) The Wheldall Assessment of Nonword Reading (WARN) Manual. Sydney: MultiLit Pty Ltd

Wiig EH, Secord W, and Semel EM (2004) CELF preschool 2: Clinical Evaluation of Language Fundamentals Preschool-Second Edition. San Antonio TX: Pearson/The Psychological Corporation.

Wilcox MJ, Gray S, and Reiser M (2020) Preschoolers with developmental speech and/or language impairment: Efficacy of the teaching early literacy and language (TELL) curriculum. Early Childhood Research Quarterly 51: 124-143.

Appendix A. Comparison of Tier 1 interventions

\begin{tabular}{|c|c|c|}
\hline & Manualised intervention & Business as usual \\
\hline Author(s) & $\begin{array}{l}\text { - Commercial publisher } \\
\text { (MultiLit) }\end{array}$ & $\begin{array}{l}\text { Speech-language pathologists, } \\
\text { with input from teachers }\end{array}$ \\
\hline $\begin{array}{l}\text { Underlying } \\
\text { frameworks }\end{array}$ & $\begin{array}{ll}\text { - } & \text { Simple View of Reading } \\
\text { (Gough and Tunmer, 1986) } \\
\text { - } & \text { Five Pillars of Reading } \\
& \text { (National Reading Panel, 2000) }\end{array}$ & $\begin{array}{l}\text { - Stackhouse and Well's } \\
\text { Phonological Processing Model } \\
\text { (1997) } \\
\text { - Schuele and Boudreau's (2008) } \\
\text { framework for phonological } \\
\text { awareness intervention }\end{array}$ \\
\hline $\begin{array}{l}\text { Approach to } \\
\text { instruction }\end{array}$ & $\begin{array}{l}\text { Explicit, direct instruction } \\
\text { - Fully scripted lessons for the } \\
\text { whole class teaching } \\
\text { component, and generic scripts } \\
\text { for some small group activities } \\
\text { - Decodable texts }\end{array}$ & $\begin{array}{l}\text { - } \\
\text { Explicit, direct instruction } \\
\text { Suggested scripted phrasing for } \\
\text { teaching specific phonemic } \\
\text { awareness skills } \\
\text { - } \\
\text { Predictable, levelled and } \\
\text { decodable texts }\end{array}$ \\
\hline
\end{tabular}




\begin{tabular}{|c|c|c|}
\hline Frequency & $\begin{array}{l}\text { - Four days per week, } 90 \text { minutes } \\
\text { per day }\end{array}$ & $\begin{array}{l}\text { - Five days per week, } 75 \text { minutes } \\
\text { per day }\end{array}$ \\
\hline $\begin{array}{l}\text { Teacher training, } \\
\text { observation and } \\
\text { support }\end{array}$ & $\begin{array}{l}\text { Formal training by program } \\
\text { authors } \\
\text { - Formal observation and } \\
\text { feedback sessions using an } \\
\text { implementation checklist }\end{array}$ & $\begin{array}{l}\text { Program induction for new staff } \\
\text { and ongoing support as } \\
\text { requested, or directed } \\
\text { - Informal observation and } \\
\text { feedback on request }\end{array}$ \\
\hline $\begin{array}{l}\text { Assessment and } \\
\text { monitoring }\end{array}$ & $\begin{array}{l}\text { - Cohort assessment and data } \\
\text { analysis at regular intervals }\end{array}$ & $\begin{array}{l}\text { - Biannual cohort assessment, and } \\
\text { progress monitoring } \\
\text { assessments at teacher discretion }\end{array}$ \\
\hline $\begin{array}{l}\text { Tier } 2 \text { and } 3 \\
\text { interventions }\end{array}$ & $\begin{array}{l}\text { - Informed by Tier } 1 \text { monitoring } \\
\text { assessments } \\
\text { - Targeted alphabetic knowledge, } \\
\text { phonemic awareness or } \\
\text { phonology }\end{array}$ & $\begin{array}{l}\text { - Informed by teacher concern } \\
\text { Targeted alphabetic knowledge, } \\
\text { phonological awareness and } \\
\text { phonology }\end{array}$ \\
\hline
\end{tabular}

